\title{
Hydrogen sulfide inhibits homocysteine-induced endoplasmic reticulum stress and neuronal apoptosis in rat hippocampus via upregulation of the BDNF-TrkB pathway
}

\author{
Hai-jun WEI ${ }^{1, \#}$, Jin-hua XU ${ }^{2, \#}$, Man-hong $\mathrm{LI}^{1,3}$, Ji-ping TANG ${ }^{1,3}$, Wei ZOU ${ }^{3}$, Ping ZHANG ${ }^{3, *}$, Li WANG ${ }^{4}$, Chun-yan WANG ${ }^{5}$, \\ Xiao-qing TANG $^{1, *}$ \\ ${ }^{1}$ Institute of Neuroscience, Medical College, University of South China, Hengyang 421001, China; ${ }^{2}$ Laboratory Center of Biochemistry \\ and Molecular Biology, University of South China, Hengyang 421001, China; ${ }^{3}$ Department of Neurology, Nanhua Affiliated Hospital, \\ University of South China, Hengyang 421001, China; ${ }^{4}$ Department of Anthropotomy, Medical College, University of South China, \\ Hengyang 421001, China; ${ }^{5}$ Department of Pathophysiology, Medical College, University of South China, Hengyang 421001, China
}

Aim: Homocysteine (Hcy) can elicit neuronal cell death, and hyperhomocysteinemia is a strong independent risk factor for Alzheimer's disease. The aim of this study was to examine the effects of hydrogen sulfide $\left(\mathrm{H}_{2} \mathrm{~S}\right)$ on Hcy-induced endoplasmic reticulum (ER) stress and neuronal apoptosis in rat hippocampus.

Methods: Adult male SD rats were intracerebroventricularly (icv) injected with Hcy $(0.6 \mu \mathrm{mol} / \mathrm{d})$ for $7 \mathrm{~d}$. Before Hcy injection, the rats were treated with NaHS (30 or $100 \mu \mathrm{mol} \cdot \mathrm{kg}^{-1} \cdot \mathrm{d}^{-1}$, ip) and/or k252a ( $1 \mathrm{\mu g} / \mathrm{d}$, icv) for $2 \mathrm{~d}$. The apoptotic neurons were detected in hippocampal coronal slices with TUNEL staining. The expression of glucose regulated protein 78 (GRP78), C/EBP homologous protein (CHOP), cleaved caspase-12, and BDNF in the hippocampus were examined using Western blotting assays. The generation of $\mathrm{H}_{2} \mathrm{~S}$ in the hippocampus was measured with the NNDPD method.

Results: Hcy markedly inhibited the production of endogenous $\mathrm{H}_{2} \mathrm{~S}$ and increased apoptotic neurons in the hippocampus. Furthermore, Hcy induced ER stress responses in the hippocampus, as indicated by the upregulation of GRP78, CHOP, and cleaved caspase-12. Treatment with the $\mathrm{H}_{2} \mathrm{~S}$ donor NaHS increased the endogenous $\mathrm{H}_{2} \mathrm{~S}$ production and BDNF expression in a dosedependent manner, and significantly reduced Hcy-induced neuronal apoptosis and ER stress responses in the hippocampus.

Treatment with k252a, a specific inhibitor of TrkB (the receptor of BDNF), abolished the protective effects of NaHS against Hcy-induced ER stress in the hippocampus.

Conclusion: $\mathrm{H}_{2} \mathrm{~S}$ attenuates ER stress and neuronal apoptosis in the hippocampus of Hcy-treated rats via upregulating the BDNF-TrkB pathway.

Keywords: hydrogen sulfide; homocysteine; neurotoxicity; hippocampus; apoptosis; ER stress; BDNF; tyrosine protein kinase B; Alzheimer's disease

Acta Pharmacologica Sinica (2014) 35: 707-715; doi: 10.1038/aps.2013.197; published online 21 Apr 2014

\section{Introduction}

Homocysteine (Hcy) is a sulfur-containing amino acid generated during methionine metabolism ${ }^{[1,2]}$. Hcy can elicit neuronal cell death in a variety of neuronal types including hippocampal and cortical neurons ${ }^{[3-5]}$, Purkinje cells ${ }^{[6]}$, cerebellar

\footnotetext{
\#These authors contributed equally to this work.

* To whom correspondence should be addressed.

E-mail tangxq01001@foxmail.com (Xiao-qing TANG); zhangp-usc@foxmail.com (Ping ZHANG)

Received 2013-09-17 Accepted 2013-12-08
}

granule cells ${ }^{[7]}$, and the human neuroblastoma cell line SH-SY5Y ${ }^{[8,9]}$. Increasingly, epidemiologic studies have established that elevated level of circulating Hcy, namely hyperhomocysteinemia, is a strong independent risk factor for Alzheimer's disease $(\mathrm{AD})^{[10-14]}$

Emerging evidence indicates that endoplasmic reticulum (ER) stress plays a pivotal role in the development or pathology of AD, which is characterized by an abnormal formation of inclusion bodies and aggregation of misfolded proteins ${ }^{[15-17]}$. The ER is a sophisticated luminal network for the synthesis, 
maturation, folding, and transportation of proteins, which are required for cell survival and normal cellular functions ${ }^{[18,19]}$. Disturbance of protein folding under various physiological or pathological conditions, such as alteration of cellular redox, deprivation of glucose, aberration of $\mathrm{Ca}^{2+}$ regulation, and viral infections, creates the ER stress ${ }^{[20]}$. Wei et al reported that exposure to Hcy of the rat embryonic heart-derived cell line $\mathrm{H} 9 \mathrm{c} 2$ can increase the expression of ER stress response genes, such as glucose regulated protein 78 (GRP78), C/EBP homologous protein $(\mathrm{CHOP})$, and cleaved caspase- $12^{[21]}$, suggesting that ER stress is involved in the mechanisms of Hcy-induced cellular dysfunction ${ }^{[8,22-25]}$. Therefore, it is logical to speculate that inhibiting Hcy-induced ER stress may be a novel therapeutic strategy to prevent and ameliorate AD progression.

Hydrogen sulfide $\left(\mathrm{H}_{2} \mathrm{~S}\right)$, the third gaseous mediator, has recently been recognized as an important endogenous neuromodulator and neuroprotectant ${ }^{[26-29]}$. The most recent in vitro studies by our group have demonstrated that Hcy-associated neurotoxicity to PC12 cells is due to reduced endogenous generation of $\mathrm{H}_{2} \mathrm{~S}^{[30]}$ and that supplementation of sodium hydrosulfide (NaHS), the $\mathrm{H}_{2} \mathrm{~S}$-donor, ameliorates the Hcy elicited-neurotoxicity in PC12 cells ${ }^{[31]}$. However, the mechanisms underlying the protective effect of $\mathrm{H}_{2} \mathrm{~S}$ against Hcy neurotoxicity are not completely understood. Recent studies have demonstrated that $\mathrm{H}_{2} \mathrm{~S}$ inhibits ER stress in apolipoprotein E knockout mice ${ }^{[32]}$ and in doxorubicin-treated $\mathrm{H} 9 \mathrm{c} 2$ cells $^{[33]}$. In addition, $\mathrm{H}_{2} \mathrm{~S}$ has been shown to attenuate 6-hydroxydopamine-induced ER stress in SH-SY5Y cell line ${ }^{[34]}$. Furthermore, $\mathrm{H}_{2} \mathrm{~S}$ could antagonize cardiomyocytic ER stress in Hcyinduced cardiomyocytic injury ${ }^{[21]}$.

The impact of $\mathrm{H}_{2} \mathrm{~S}$ on ER stress involved in the neurotoxicity of Hcy is not yet known. Given the importance of Hcy in the pathogenesis of $\mathrm{AD}$ and the elevated ER stress response to Hcy, it is imperative to understand if the Hcy-induced ER stress status of neurocytes is regulated by $\mathrm{H}_{2} \mathrm{~S}$ and to investigate the underlying mechanisms. Brain-derived neurotrophic factor (BDNF), a neurotrophic factor acting on the central nervous system, prevents ordinary types of neuronal cell death induced by various stimulants. Increasing evidence has demonstrated that prevention of ER stress contributes to BDNF-mediated neuroprotection ${ }^{[35-37]}$. Therefore, the present study was undertaken to examine whether $\mathrm{H}_{2} \mathrm{~S}$ could regulate Hcy-induced neuronal ER stress in a rat model of Hcy neurotoxicity in vivo. Furthermore, the involvement of the BDNFtyrosine protein kinase $B(\operatorname{TrkB})$ pathway in $\mathrm{H}_{2} \mathrm{~S}$-attenuated ER stress induced by Hcy was also investigated. In this study, we demonstrated for the first time the protective effects of $\mathrm{H}_{2} \mathrm{~S}$ against Hcy-induced ER stress in the hippocampus of rats and that the underlying mechanism involves the upregulation of the BDNF-TrkB pathway.

\section{Materials and methods Reagents}

NaHS, Hcy, and k252a (an inhibitor of the BDNF receptor TrkB) were purchased from Sigma-Aldrich (St Louis, MO, USA). The in situ apoptosis detection kit was supplied by
Roche Diagnostics (Indianapolis, IN, USA). Specific monoclonal anti-BDNF, anti-GRP78, and anti-CHOP antibodies were purchased from Epitomics Inc (Burlingame, CA, USA). Specific monoclonal anti-caspase-12 antibody was obtained from Sigma-Aldrich. RPMI-1640 medium, horse serum, and fetal bovine serum (FBS) were supplied by Gibco BRL (Grand Island, NY, USA).

\section{Cell culture}

PC12 cells, originally derived from a transplantable rat pheochromocytoma, were supplied by Sun Yat-sen University Experimental Animal Center (Guangzhou, China) and maintained on tissue culture plastic in RPMI-1640 medium supplemented with 10\% heat-inactivated horse serum and 5\% FBS at $37^{\circ} \mathrm{C}$ under an atmosphere of $5 \% \mathrm{CO}_{2}$ and $95 \%$ air. The culture medium was changed three times per week.

\section{Animals}

Adult male Sprague-Dawley rats (250-280 g), obtained from the SJA Lab Animal Center of Changsha (Changsha, China), were housed individually in a temperature- and humiditycontrolled room and kept on a 12-h light/12-h dark cycle with free access to food and water. The rats were handled (2-3 min per rat per day) for one week to be accustomed to the experimenter. Experiments were conducted in accordance with the National Institute of Health's Guide for the Care and Use of Laboratory Animals and were approved by the Animal Use and Protection Committee of University of South China. All efforts were made to minimize animal's suffering.

\section{Drugs and treatments}

$\mathrm{Hcy}$ and $\mathrm{NaHS}$ were dissolved in $0.9 \%$ nonpyrogenic $\mathrm{NaCl}$ and the solution was filtered through a $0.2-\mu \mathrm{m}$ PTFE filter (Sigma-Aldrich). K252a was dissolved in sterilized artificial cerebrospinal fluid/dimethyl sulfoxide (ACSF/DMSO; volum ratio, 1:1) (Sigma-Aldrich). Hcy and k252a were injected intracerebroventricularly (icv), and NaHS was injected intraperitoneally (ip). Rats were divided into four treatment groups: 1) a control group, in which subjects were treated with saline (ip) and ACSF/DMSO (icv) every day for $9 \mathrm{~d}$; 2) an Hcy-treated alone group, in which subjects were treated with $0.6 \mu \mathrm{mol} / \mathrm{d}$ Hcy (icv) for $7 \mathrm{~d}$; 3) a co-treated with Hcy and NaHS group, in which subjects were pretreated with 30 or $100 \mu \mathrm{mol} \cdot \mathrm{kg}^{-1} \cdot \mathrm{d}^{-1}$ NaHS (ip) for $2 \mathrm{~d}$ and then co-treated with $0.6 \mu \mathrm{mol} / \mathrm{d}$ Hcy (icv) for $7 \mathrm{~d}$; and 4) a k252a-inhibition group, in which subjects were pretreated with 30 or $100 \mu \mathrm{mol} / \mathrm{kg}$ NaHS (ip) and $1 \mu \mathrm{g} / \mathrm{d} \mathrm{k} 252 \mathrm{a}$ (icv) for $2 \mathrm{~d}$ and then co-treated with $0.6 \mu \mathrm{mol}$ Hcy (icv) per day for $7 \mathrm{~d}$. The intraperitoneal treatments were administered in a volume of $1 \mathrm{~mL} / \mathrm{kg}$ body weight. The intracerebroventricular treatments were administered in a volume of $2.5 \mu \mathrm{L}$.

\section{Intracerebroventricular injection}

The rats were anesthetized with sodium pentobarbital (45 $\mathrm{mg} / \mathrm{kg}$, ip) and placed into a stereotaxic apparatus for operation. Saline, ACSF/DMSO, Hcy $(0.6 \mu \mathrm{mol})$, or k252a $(1 \mu \mathrm{g})$ 
with a volume of $2.5 \mu \mathrm{L}$ was injected into the bilateral ventricle at the following coordinates: anterior/posterior -1.4 $\mathrm{mm}$, medial/lateral $1.8 \mathrm{~mm}$, dorsal/ventral $-3.0 \mathrm{~mm}$ from the bregma, respectively, with an injection rate of $0.5 \mu \mathrm{L} /$ min under the control of a micropump. To ensure that the entire injection had been delivered, the injection cannula was allowed to remain in place for an additional minute before being removed.

\section{TdT-mediated dUTP nick-end labeling (TUNEL) staining}

After anesthesia, rats were fixed by perfusing $200-300 \mathrm{~mL}$ of Zamboni's fixative (4\% paraformaldehyde in $0.1 \mathrm{~mol} / \mathrm{L}$ phosphate buffer, $\mathrm{pH}=7.4$ ) through the left ventricle of the heart. The hippocampus was removed and post-fixed in the perfusion fixative for $2 \mathrm{~h}$ at room temperature and then immersed in a $20 \%$ sucrose solution until the tissue sank. The hippocampus was coronally sectioned with a cryostat at a thickness of $10 \mu \mathrm{m}$.

To detect the apoptotic cell death in the hippocampus, we processed the sections of the hippocampus for TUNEL staining using an in situ apoptosis detection kit (Roche Diagnostics). Briefly, sections were digested with $15 \mu \mathrm{g} / \mathrm{mL}$ proteinase $\mathrm{K}$ for $15 \mathrm{~min}$ at room temperature and then washed with phosphate buffered saline (PBS). Endogenous peroxidase activity was quenched with $3 \% \mathrm{H}_{2} \mathrm{O}_{2}$ for $5 \mathrm{~min}$ at room temperature. After being washed with PBS, the sections were immersed in terminal deoxynucleotidyl transferase (TdT) labeling buffer, covered with TdT buffer containing TdT, $1 \mathrm{mmol} / \mathrm{L} \mathrm{Mn}^{2+}$, and biotinylated dNTP, and incubated in a humid atmosphere at $37^{\circ} \mathrm{C}$ for $90 \mathrm{~min}$ before being washed with PBS. The sections were then incubated with streptavidin-horseradish peroxidase for $30 \mathrm{~min}$. The sections were rinsed with PBS, and immersed in diaminobenzidine solution. The slides were counterstained for 1 min with $1 \%$ methyl green. The total number of TUNELpositive cells on each section was counted under a microscope. The data are presented as the number of positive neurons $/ \mathrm{mm}^{2}$.

\section{Assay of $\mathrm{H}_{2} \mathrm{~S}$ generation}

The hippocampus was homogenized in $50 \mathrm{mmol} / \mathrm{L}$ ice-cold potassium phosphate buffer $(\mathrm{pH}$ 6.8). The reaction mixture contained potassium phosphate buffer ( $\mathrm{pH} 7.4,100 \mathrm{mmol} / \mathrm{L})$, L-cysteine $(20 \mu \mathrm{L}, 10 \mathrm{mmol} / \mathrm{L})$, pyridoxyal 5' -phosphate (20 $\mu \mathrm{L}, 2 \mathrm{mmol} / \mathrm{L})$, saline $(30 \mu \mathrm{L})$, and tissue homogenate $(430 \mu \mathrm{L}$, $11 \% w / v)$. The reaction was performed in tightly stoppered cryovial test tubes and initiated by transferring the tubes from ice to a shaking water bath at $37^{\circ} \mathrm{C}$. After incubation for $30 \mathrm{~min}$, zinc acetate $(250 \mu \mathrm{L}, 1 \% \mathrm{w} / \mathrm{v})$ was added to trap evolved $\mathrm{H}_{2} \mathrm{~S}$ followed by trichloroacetic acid $(250 \mu \mathrm{L}, 10 \% v / v)$ to denature the protein and stop the reaction. Subsequently, $N, N$-dimethyl-p-phenylenediamine sulfate (NNDPD; $133 \mu \mathrm{L}$, $20 \mu \mathrm{mol} / \mathrm{L}$ ) in $7.2 \mathrm{~mol} / \mathrm{L} \mathrm{HCl}$ was added, immediately followed by $\mathrm{FeCl}_{3}(133 \mu \mathrm{L}, 30 \mu \mathrm{mol} / \mathrm{L})$ in $1.2 \mathrm{~mol} / \mathrm{L} \mathrm{HCl}$. The absorbance of the resulting solution at $670 \mathrm{~nm}$ was measured by spectrophotometry. The $\mathrm{H}_{2} \mathrm{~S}$ concentration was calculated against a calibration curve of $\mathrm{NaHS}$, and $\mathrm{H}_{2} \mathrm{~S}$ synthesizing activity was determined using a BCA Protein Assay Kit (Beyo- time, Shanghai, China) and expressed as micromoles of $\mathrm{H}_{2} \mathrm{~S}$ formed from $1 \mathrm{~g}$ protein per minute $\left(\mathrm{nmol} \cdot \mathrm{min}^{-1} \cdot \mathrm{mg}^{-1}\right.$ protein).

\section{SDS-PAGE and Western blotting analysis}

Hippocampal tissues were homogenized in an ice-cold lysis buffer [20 mmol/L Tris- $\mathrm{HCl}$ (pH 7.5), $150 \mathrm{mmol} / \mathrm{L} \mathrm{NaCl}$, $1 \%$ Triton X-100, $1 \mathrm{mmol} / \mathrm{L}$ phenylmethylsulfonylfluoride (PMSF), $1 \mathrm{mmol} / \mathrm{L} \mathrm{Na}_{3} \mathrm{VO}_{4}$, leupeptin, and EDTA]. Then, the samples were centrifuged at 14000 rounds/min for $30 \mathrm{~min}$ at $4^{\circ} \mathrm{C}$, and the supernatant was collected. The protein concentration was assessed using a BCA Protein Assay Kit (Beyotime). Equivalent amount of protein for each sample was run on sodium dodecyl sulfate-polyacrylamide gel electrophoresis (SDS-PAGE). The protein was then transferred to a PVDF membrane and blocked in TBST buffer [50 mmol/L Tris- $\mathrm{HCl}$ (pH 7.5), $150 \mathrm{mmol} / \mathrm{L} \mathrm{NaCl}, 0.05 \%$ Tween-20] containing 5\% bovine serum albumin for $2 \mathrm{~h}$. The membrane was incubated with blocking solution containing primary antibody (antiCHOP, 1:500; anti-GRP78, 1:2000; anti-caspase-12, 1:2000; or anti-BDNF, 1:2000) overnight at $4{ }^{\circ} \mathrm{C}$. After being washed with TBST-buffer, the membrane was incubated in anti-rabbit secondary antibody conjugated to horseradish peroxidase (1:5000) in blocking solution for $2 \mathrm{~h}$. Next, the membrane was washed with TBST buffer and incubated in the electrogenerated chemiluminescence reaction solutions (solution 1: $0.1 \mathrm{~mol} / \mathrm{L}$ Tris- $\mathrm{HCl}$, luminol, p-coumaric acid; solution 2: 0.1 $\mathrm{mol} / \mathrm{L}$ Tris- $\mathrm{HCl}$, hydrogen peroxide) for $2 \mathrm{~min}$. The signal of the immunoblots was visualized using an image analysis system equipped with the software BIO-ID (Vilber Lourmat, Marne-la-Vallée, France).

\section{Statistical analysis}

Data are expressed as the mean \pm SEM. The significance of inter-group differences was evaluated by one-way analysis of variance (ANOVA), followed by a Newman-Keuls test. Differences were considered significant at two-tailed $P<0.05$.

\section{Results}

$\mathrm{H}_{2} \mathrm{~S}$ attenuates Hcy-induced neuronal apoptosis in the hippocampal CA1 region

We first detected the apoptotic cells in the hippocampus slices by TUNEL staining to confirm the protection of $\mathrm{H}_{2} \mathrm{~S}$ against Hcy-induced neurotoxicity in vivo. As shown in Figure 1, after 7 -d treatment with Hcy $(0.6 \mu \mathrm{mol} / \mathrm{d}$, icv $)$, significant amounts of TUNEL-positive neurons appeared in the hippocampal CA1 region in the rats. However, the TUNEL-positive neurons in the hippocampal CA1 region were markedly decreased in the rats pretreated with NaHS $\left(100 \mu \mathrm{mol} \cdot \mathrm{kg}^{-1} \cdot \mathrm{d}^{-1}\right.$ for $2 \mathrm{~d}$, ip) and then co-treated with Hcy $(0.6 \mu \mathrm{mol} / \mathrm{d}$ for $7 \mathrm{~d}$, icv).

\section{$\mathrm{H}_{2} \mathrm{~S}$ upregulates BDNF expression in hippocampus of rats}

To explore if the upregulation of BDNF is involved in the mechanism underlying the protective effect of $\mathrm{H}_{2} \mathrm{~S}$ against Hcy-elicited neurotoxicity, we investigated the effect of $\mathrm{H}_{2} \mathrm{~S}$ on BDNF expression in the hippocampus of rats. BDNF expression was markedly downregulated in the hippocampus of rats 
A


B

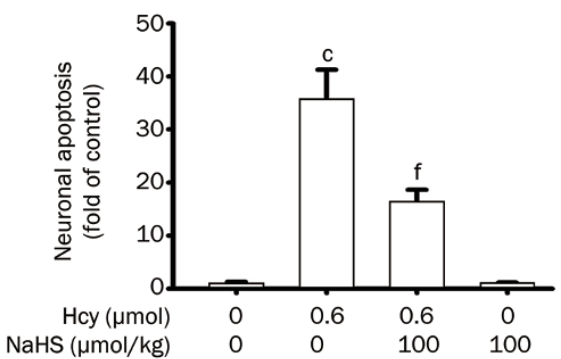

Figure 1. Effect of NaHS on Hcy-induced neuronal apoptosis in the hippocampal CA1 region of rats. Rats were pretreated with NaHS (100 $\mu \mathrm{mol} \cdot \mathrm{kg}^{-1} \cdot \mathrm{d}^{-1}$ for $2 \mathrm{~d}$, ip) and then co-treated with Hcy $(0.6 \mu \mathrm{mol} / \mathrm{d}$ for $7 \mathrm{~d}$, icv), and the hippocampus was processed for TUNEL staining using an in situ apoptosis detection kit. (A) Representative images of TUNEL staining of the hippocampus in different treatment groups (100×objective, BX50FLA, Olympus). Arrows indicate the apoptotic neurons. (B) TUNEL-positive neuron counts in the hippocampus under different treatments. Values are expressed as the mean \pm SEM $(n=5) .{ }^{c} P<0.01$ vs non-treated control group. ${ }^{f} P<0.01$ vs Hcy-treated alone group.

treated with Hcy $(0.6 \mu \mathrm{mol} / \mathrm{d}$ for $7 \mathrm{~d}$, icv $)$. However, BDNF expression was reversed in the hippocampus of rats pretreated with NaHS (30 and $100 \mu \mathrm{mol} \cdot \mathrm{kg}^{-1} \cdot \mathrm{d}^{-1}$ for $2 \mathrm{~d}$, ip) and then cotreated with Hcy $(0.6 \mu \mathrm{mol} / \mathrm{d}$ for $7 \mathrm{~d}$, icv) (Figure 2A). In addition, the expression of BDNF was upregulated in the hippocampus of rats treated with NaHS $\left(30\right.$ and $100 \mu \mathrm{mol} \cdot \mathrm{kg}^{-1} \cdot \mathrm{d}^{-1}$ for $9 \mathrm{~d}$, ip) (Figure 2B).

$\mathrm{H}_{2} \mathrm{~S}$ decreases Hcy-induced upregulation of GRP78 expression in the hippocampus of rats, and this effect is abolished by blocking the BDNF-TrkB pathway

To investigate whether Hcy induces ER stress in the hippocampus of rats and whether $\mathrm{H}_{2} \mathrm{~S}$ inhibits Hcy-induced ER stress, we first sought to explore the expression of GRP78, an important marker for ER stress, in the hippocampus of rats. As shown in Figure 3A, Hcy $(0.6 \mu \mathrm{mol} / \mathrm{d}$ for $7 \mathrm{~d}$, icv) significantly increased GRP78 expression in the hippocampus of rats. However, pretreatment with NaHS $\left(30\right.$ and $100 \mu \mathrm{mol} \cdot \mathrm{kg}^{-1} \cdot \mathrm{d}^{-1}$ for $2 \mathrm{~d}$, ip) before the co-treatment with Hcy for $7 \mathrm{~d}$ clearly decreased the upregulated expression of GRP78 induced by
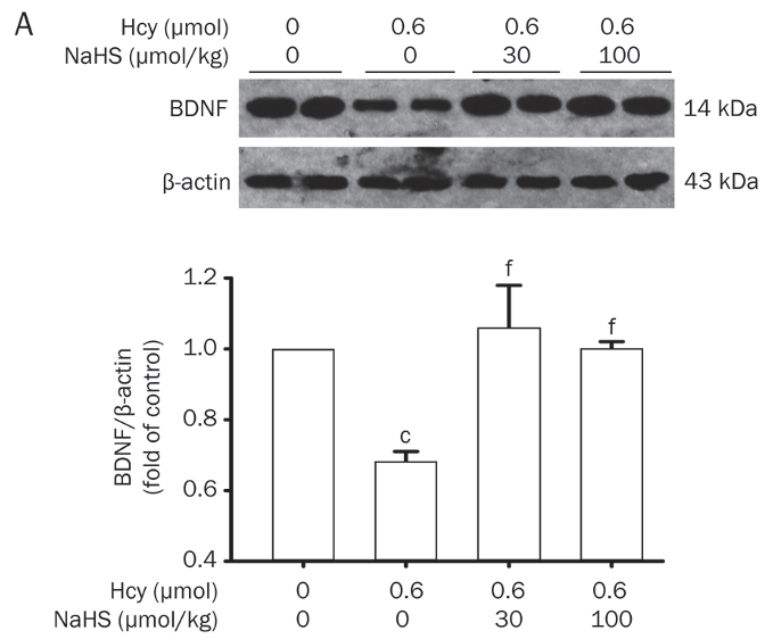

B
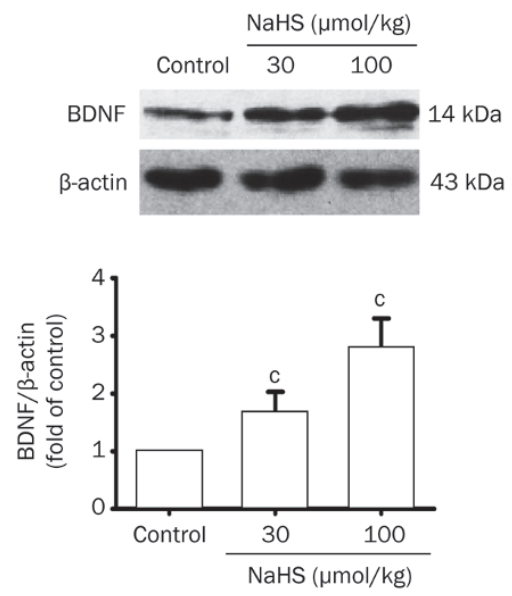

Figure 2. NaHS upregulates the expression of BDNF in the hippocampus of rats. (A) Rats were pretreated with $\mathrm{NaHS}\left(30\right.$ and $100 \mu \mathrm{mol} \cdot \mathrm{kg}^{-1} \cdot \mathrm{d}^{-1}$ for $2 \mathrm{~d}$, ip) and then co-treated with Hcy $(0.6 \mu \mathrm{mol} / \mathrm{d}$ for $7 \mathrm{~d}$, icv). (B) Rats were treated with NaHS (30 and $100 \mu \mathrm{mol} \cdot \mathrm{kg}^{-1} \cdot \mathrm{d}^{-1}$ for $9 \mathrm{~d}$, ip). The expression of BDNF in the hippocampus of rats was detected by Western blotting using an anti-BDNF antibody, and $\beta$-actin was used as a loading control. Values are expressed as the mean \pm SEM $(n=3-5) .{ }^{c} P<0.01$ vs control group. ${ }^{f} P<0.01$ vs Hcy-treated alone group.

Hcy. These findings indicate the effects of Hcy on ER stress in the hippocampus and the inhibitory effect of $\mathrm{H}_{2} \mathrm{~S}$ on Hcyinduced ER stress.

To determine the involvement of the BDNF-TrkB pathway in $\mathrm{H}_{2} \mathrm{~S}$ neuroprotection against Hcy-induced ER stress, we investigated the effect of k252a on the inhibitory role of $\mathrm{H}_{2} \mathrm{~S}$ in Hcy-upregulated GRP78 expression. As shown in Figure 3B, treatment with k252a $(1 \mu \mathrm{g} / \mathrm{d}$ for $9 \mathrm{~d}$, icv) dramatically curbed the preventive effects of NaHS $\left(100 \mu \mathrm{mol} \cdot \mathrm{kg}^{-1} \cdot \mathrm{d}^{-1}\right.$ for $9 \mathrm{~d}$, ip) on the expression of GRP78 in the hippocampus of rats treated with Hcy $(0.6 \mu \mathrm{mol} / \mathrm{d}$ for $7 \mathrm{~d}$, icv), indicating that the protective effect of $\mathrm{H}_{2} \mathrm{~S}$ against Hcy-induced ER stress is mediated by stimulation of the BDNF-TrkB pathway. 

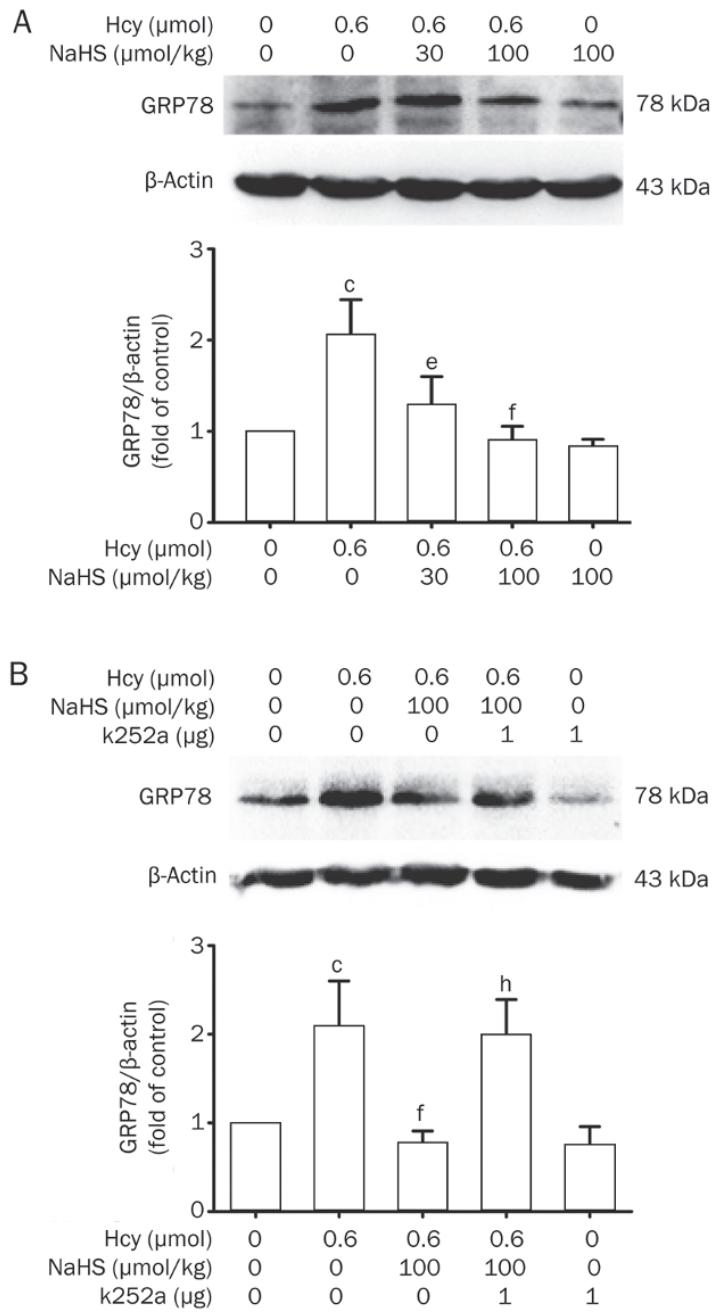

Figure 3. NaHS decreases Hcy-upregulated GRP78 expression in the hippocampus of rats, and this effect is abolished by k252a, a specific inhibitor of the BDNF receptor TrkB. (A) Rats were pretreated with NaHS (30 and $100 \mu \mathrm{mol} \cdot \mathrm{kg}^{-1} \cdot \mathrm{d}^{-1}$ for $2 \mathrm{~d}$, ip) and then co-treated with Hcy $(0.6 \mu \mathrm{mol} / \mathrm{d}$ for $7 \mathrm{~d}$, icv). (B) Rats were pretreated with NaHS (30 and $100 \mu \mathrm{mol} \cdot \mathrm{kg}^{-1} \cdot \mathrm{d}^{-1}$ for $2 \mathrm{~d}$, ip) in the absence or presence of treatment with $\mathrm{k} 252 \mathrm{a}(1 \mathrm{\mu g} / \mathrm{d}$ for $2 \mathrm{~d}$, icv) and then co-treated with Hcy $(0.6 \mu \mathrm{mol} / \mathrm{d}$ for $7 \mathrm{~d}$, icv). The expression of GRP78 in the hippocampus was detected by Western blotting using an anti-GRP78 antibody, and $\beta$-actin was used as a loading control. Values are expressed as the mean \pm SEM $(n=3-5) .{ }^{c} P<0.01$ vs control group. ${ }^{\mathrm{e}} P<0.05,{ }^{\mathrm{f}} P<0.01$ vs Hcy-treated alone group. ${ }^{\mathrm{h}} P<0.05$ vs co-treated with Hcy and NaHS group.

$\mathrm{H}_{2} \mathrm{~S}$ represses Hcy-induced upregulation of CHOP expression in hippocampus of rats, and this effect is blocked by inhibiting the BDNF-TrkB pathway

To further ascertain whether exposure to Hcy induces ER stress, we proceeded to monitor the CHOP protein level in the hippocampus of rats. $\mathrm{CHOP}$ expression in the hippocampus of rats treated with Hcy $(0.6 \mu \mathrm{mol} / \mathrm{d}$ for $7 \mathrm{~d}$, icv) was clearly increased. However, upregulated CHOP expression was attenuated in the hippocampus of rats by pretreating with NaHS (30 and $100 \mu \mathrm{mol} \cdot \mathrm{kg}^{-1} \cdot \mathrm{d}^{-1}$ for $2 \mathrm{~d}$, ip) before co-treatment with Hcy $(0.6 \mu \mathrm{mol} / \mathrm{d}$ for $7 \mathrm{~d}$, icv) (Figure $4 \mathrm{~A})$. These data


Figure 4. NaHS suppresses Hcy-upregulated CHOP expression in the hippocampus of rats, and this effect is blocked by k252a. (A) Rats were pretreated with NaHS (30 and $100 \mu \mathrm{mol} \cdot \mathrm{kg}^{-1} \cdot \mathrm{d}^{-1}$ for $2 \mathrm{~d}$, ip) and then cotreated with Hcy $(0.6 \mu \mathrm{mol} / \mathrm{d}$ for $7 \mathrm{~d}$, icv). (B) Rats were pretreated with NaHS (30 and $100 \mu \mathrm{mol} \cdot \mathrm{kg}^{-1} \cdot \mathrm{d}^{-1}$ for $2 \mathrm{~d}$, ip) in the absence or presence of treatment with $\mathrm{k} 252 \mathrm{a}(1 \mathrm{\mu g} / \mathrm{d}$ for $2 \mathrm{~d}$, icv) and then co-treated with Hcy $(0.6 \mu \mathrm{mol} / \mathrm{d}$ for $7 \mathrm{~d}$, icv). The expression of CHOP in the hippocampus of rats was detected by Western blotting using an anti-CHOP antibody, and $\beta$-actin was used as a loading control. Values are expressed as the mean \pm SEM ( $n=3-5)$. ${ }^{c} P<0.01$ vs control group. ${ }^{e} P<0.05,{ }^{f} P<0.01$ vs Hcytreated alone group. $\mathrm{i} P<0.01$ vs co-treated with Hcy and NaHS group.

also indicated the protective action of $\mathrm{H}_{2} \mathrm{~S}$ on Hcy-induced ER stress.

We also explored the effect of k252a on the suppressive role of $\mathrm{H}_{2} \mathrm{~S}$ in Hcy-upregulated CHOP expression. Western blotting analysis revealed that administration of k252a $(1 \mu \mathrm{g} / \mathrm{d}$, icv, for $9 \mathrm{~d})$ prevented NaHS $\left(100 \mu \mathrm{mol} \cdot \mathrm{kg}^{-1} \cdot \mathrm{d}^{-1}\right.$ for $9 \mathrm{~d}$, ip) from suppressing the expression of $\mathrm{CHOP}$ in the hippocampus of rats treated with Hcy $(0.6 \mu \mathrm{mol} / \mathrm{d}$ for $7 \mathrm{~d}$, icv) (Figure $4 \mathrm{~B})$. This suggests an important role of the BDNF-TrkB pathway in mediating the neuroprotective effect of $\mathrm{H}_{2} \mathrm{~S}$ against ER stress induced by Hcy. 

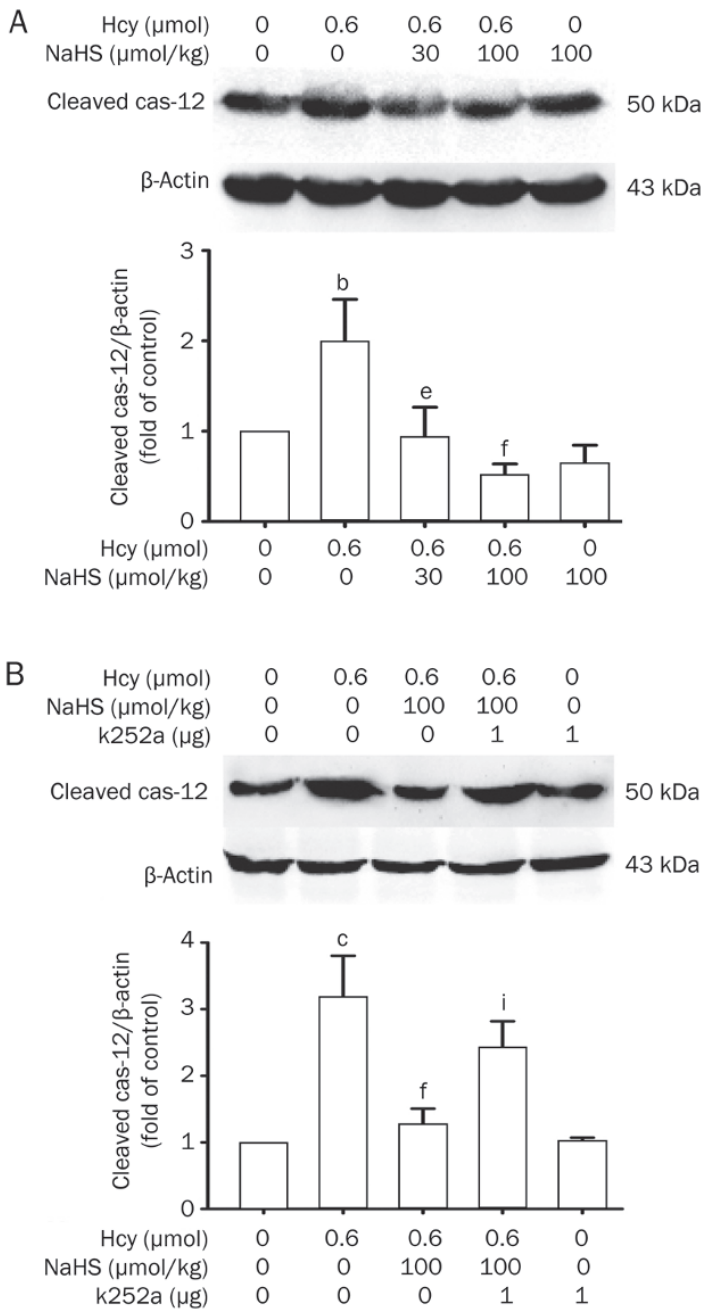

Figure 5. NaHS suppresses Hcy-upregulated cleaved caspase-12 expression in the hippocampus of rats, and this effect is blocked by k252a. (A) Rats were pretreated with NaHS (30 and $100 \mu \mathrm{mol} \cdot \mathrm{kg}^{-1} \cdot \mathrm{d}^{-1}$ for $2 \mathrm{~d}$, ip) and then co-treated with Hcy $(0.6 \mu \mathrm{mol} / \mathrm{d}$ for $7 \mathrm{~d}$, icv). (B) Rats were pretreated with NaHS (30 and $100 \mu \mathrm{mol} \cdot \mathrm{kg}^{-1} \cdot \mathrm{d}^{-1}$ for $2 \mathrm{~d}$, ip) in the absence or presence of treatment with k252a ( $1 \mu \mathrm{g} / \mathrm{d}$ for $2 \mathrm{~d}$, icv) and then co-treated with $\mathrm{Hcy}(0.6 \mu \mathrm{mol} / \mathrm{d}$ for $7 \mathrm{~d}$, icv). The expression of cleaved caspase-12 in the hippocampus of rats were detected by Western blotting using an anti-cleaved caspase- 12 antibody, and $\beta$-actin was used as a loading control. Values are expressed as the mean \pm SEM $(n=3-5)$. ${ }^{\mathrm{b}} P<0.05,{ }^{\mathrm{c} P}<0.01$ vs control group. ${ }^{\mathrm{e}} P<0.05,{ }^{\mathrm{f}} P<0.01$ vs Hcy-treated alone group. ' $P<0.01$ vs co-treated with Hcy and NaHS group.

$\mathrm{H}_{2} \mathrm{~S}$ reduces Hcy-induced upregulation of cleaved caspase-12 expression in hippocampus of rats, and this effect is blocked by inhibition of the BDNF-TrkB pathway

Cleaved caspase-12 participates in ER stress-induced apoptosis. Therefore, we further investigated the expression of cleaved caspase-12 in the hippocampus of rats. As shown in Figure 5A, Hcy $(0.6 \mu \mathrm{mol} / \mathrm{d}$ for $7 \mathrm{~d}$, icv) significantly upregulated the expression of cleaved caspase- 12 in the hippocampus of rats. However, pretreatment with NaHS (30 and 100 $\mu \mathrm{mol} \cdot \mathrm{kg}^{-1} \cdot \mathrm{d}^{-1}$ for $2 \mathrm{~d}$, ip) before co-treatment with Hcy for $7 \mathrm{~d}$ clearly suppressed the upregulation of cleaved caspase-12 induced by Hcy. These data suggested that $\mathrm{H}_{2} \mathrm{~S}$ treatment produces a protective role in ER stress-induced apoptosis.

We further investigated the effect of k252a on the inhibitory role of $\mathrm{H}_{2} \mathrm{~S}$ in Hcy-upregulated expression of cleaved caspase-12. As shown in Figure 5B, administration of the inhibitor of the BDNF receptor $\mathrm{k} 252 \mathrm{a}(1 \mu \mathrm{g} / \mathrm{d}$ for $9 \mathrm{~d}$, icv) prevented NaHS $\left(100 \mu \mathrm{mol} \cdot \mathrm{kg}^{-1} \cdot \mathrm{d}^{-1}\right.$ for $9 \mathrm{~d}$, ip) from inhibiting the upregulated expression of cleaved caspase-12 in the hippocampus of rats treated with Hcy $(0.6 \mu \mathrm{mol} / \mathrm{d}$ for $7 \mathrm{~d}$, icv). This suggests that the BDNF-TrkB pathway mediates the neuroprotective effect of $\mathrm{H}_{2} \mathrm{~S}$ against Hcy-induced ER stress.

\section{$\mathrm{H}_{2} \mathrm{~S}$ prevents Hcy-induced ER stress in PC12 cells}

To further confirm the protective effect of $\mathrm{H}_{2} \mathrm{~S}$ against Hcyinduced ER stress, we investigated the effects of $\mathrm{H}_{2} \mathrm{~S}$ on Hcyinduced ER stress in PC12 cells. As illustrated in Figure 6, pretreatment with NaHS (200 $\mu \mathrm{mol} / \mathrm{L})$ for $30 \mathrm{~min}$ significantly attenuated the increases in the expression levels of GRP78, CHOP, and cleaved caspase-12 in PC12 cells induced by treatment with $5 \mathrm{mmol} / \mathrm{L}$ of Hcy for $24 \mathrm{~h}$. These data confirm the protective effect of $\mathrm{H}_{2} \mathrm{~S}$ against Hcy-induced ER stress in vitro.

Hcy inhibits endogenous hippocampal $\mathrm{H}_{2} \mathrm{~S}$ production, which is reversed by NaHS administration

To know the feedback effect of ER stress on $\mathrm{H}_{2} \mathrm{~S}$ production in the hippocampus, we explored the level of hippocampal endogenous $\mathrm{H}_{2} \mathrm{~S}$ production in the rats treated with Hcy and the restorative effect of NaHS administration. As shown in Figure 7, the generation of $\mathrm{H}_{2} \mathrm{~S}$ in the hippocampus of rats treated with Hcy $(0.6 \mu \mathrm{mol} / \mathrm{d}$ for $7 \mathrm{~d}$, icv) was markedly inhibited. However, the generation of $\mathrm{H}_{2} \mathrm{~S}$ in the hippocampus of rats was rescued by pretreating with NaHS (30 and $100 \mu \mathrm{mol} \cdot \mathrm{kg}^{-1} \cdot \mathrm{d}^{-1}$ for $2 \mathrm{~d}$, ip) before co-treatment with Hcy $(0.6$ $\mu \mathrm{mol} / \mathrm{d}$ for $7 \mathrm{~d}, \mathrm{icv})$.

\section{Discussion}

$\mathrm{H}_{2} \mathrm{~S}$ is an emerging novel endogenous neuroprotectant. We have previously demonstrated the protective effect of $\mathrm{H}_{2} \mathrm{~S}$ against the neurotoxicity of Hcy. The present study was designed to investigate the role of $\mathrm{H}_{2} \mathrm{~S}$ in regulating Hcyinduced neuronal ER stress and the underlying mechanisms. We showed that $\mathrm{H}_{2} \mathrm{~S}$ upregulates the expression of BDNF in the hippocampus of rats and that intracerebroventricular injection of Hcy leads to an increase in the expression of various ER stress-associated proteins, including GRP78, CHOP, and cleaved caspase-12, in the hippocampus of rats. Notably, we found that $\mathrm{H}_{2} \mathrm{~S}$ was able to downregulate the elevated ER stress markers. Furthermore, blocking of the BDNF-TrkB pathway by the inhibitor of TrkB, k252a, reverses the protective role of $\mathrm{H}_{2} \mathrm{~S}$ in Hcy-induced ER stress. Collectively, these findings suggest that $\mathrm{H}_{2} \mathrm{~S}$ could attenuate neuronal ER stress in Hcy-induced neurotoxicity by upregulating the pathway of BDNF-TrkB.

$\mathrm{Hcy}$ is an independent risk factor for $\mathrm{AD}^{[10-14]}$. ER stress is implicated in the development or pathology of $\mathrm{AD}^{[15-17]}$. 



B


Figure 6. NaHS suppresses Hcy-induced ER stress in PC12 cells. After pretreatment with NaHS $(200 \mu \mathrm{mol} / \mathrm{L})$ for $30 \mathrm{~min}, \mathrm{PC} 12$ cells were exposed to Hcy ( $5 \mathrm{mmol} / \mathrm{L})$ for $24 \mathrm{~h}$. The levels of GRP78 (A), CHOP (B), and cleaved caspase-12 (C) expression in PC12 cells were detected by Western blotting using anti-GRP78, -CHOP, and -cleaved caspase-12 antibody, respectively. In all blots, staining for $\beta$-actin was used as a loading control. Values are presented as the mean $\pm \operatorname{SEM}(n=3) .{ }^{c} P<0.01$ vs control group. ${ }^{f} P<0.01$ vs Hcy-treated alone group.

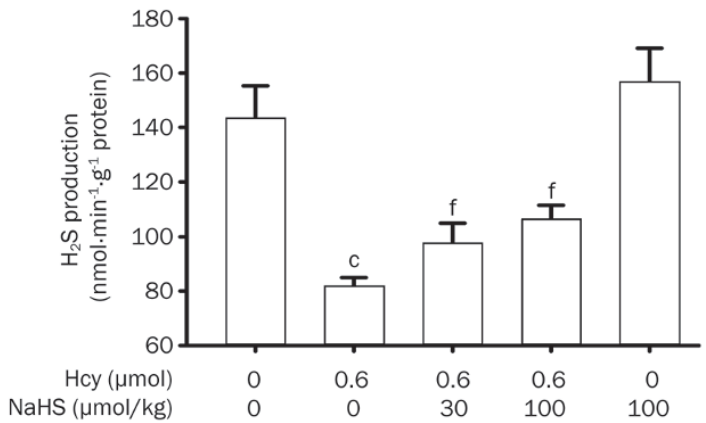

Figure 7. Hcy inhibits hippocampal endogenous $\mathrm{H}_{2} \mathrm{~S}$ generation, which is rescued by the administration of NaHS. Rats were pretreated with $\mathrm{NaHS}$ (30 and $100 \mu \mathrm{mol} \cdot \mathrm{kg}^{-1} \cdot \mathrm{d}^{-1}$ for $2 \mathrm{~d}$, ip) and then co-treated with Hcy $(0.6 \mu \mathrm{mol} / \mathrm{d}$ for $7 \mathrm{~d}$, icv). The hippocampus of rats was homogenized and the generation of $\mathrm{H}_{2} \mathrm{~S}$ in the hippocampus was measured by the NNDPD method as described in the Materials and Methods section. Values are expressed as the mean \pm SEM $(n=3-5)$. ${ }^{c} P<0.01$ vs control group. ${ }^{f} P<0.01$ vs Hcy-treated alone group.

Although it is not clear if Hcy triggers neuronal ER stress, ER stress has been proposed to explain the pathogenic effects of Hcy in cardiovascular disease $\mathrm{e}^{[21]}$, insulin resistance of adipose tissue $^{[38]}$, apoptosis of osteoblastic cells ${ }^{[39]}$, type 2 diabetes mellitus ${ }^{[40]}$, and hepatic steatosis ${ }^{[4]]}$. ER stress may be a common pathway of the injury of tissues and cells induced by Hcy. In the present work, we examined the effects of Hcy on the expression of protein markers of ER stress, such as GRP78, $\mathrm{CHOP}$, and cleaved caspase-12, in the hippocampus of rats. We found that expressions of GRP78, CHOP, and cleaved caspase-12 in the hippocampus of rats were all upregulated by intracerebroventricular injection of Hcy. This indicated that Hcy-induced, severe ER stress was present in the hippocampus, suggesting that ER stress is a contributory factor in Hcyinduced neurotoxicity.

Interestingly, $\mathrm{H}_{2} \mathrm{~S}$ and Hcy are metabolites of methionine ${ }^{[22]}$, but they exert entirely opposite effects on the viability of neurocytes. Hcy induces accumulation of reactive oxygen species (ROS) and stimulates neurotoxicity ${ }^{[43,44]}$, whereas $\mathrm{H}_{2} \mathrm{~S}$ scavenges ROS and protects neurons against oxidative stress ${ }^{[45-48]}$. Furthermore, both elevation of Hcy and decrease of $\mathrm{H}_{2} \mathrm{~S}$ are detected in the brains of AD patients ${ }^{[49]}$. Therefore, we have previously explored if $\mathrm{H}_{2} \mathrm{~S}$ directly antagonizes the toxicity of Hcy to neuronal cells, and our previous data revealed that $\mathrm{H}_{2} \mathrm{~S}$ could attenuate the neurotoxicity of $\mathrm{Hcy}^{[31]}$. It has been reported that $\mathrm{H}_{2} \mathrm{~S}$ serves as a protective gaseous signaling molecule in the nervous system by preserving mitochondrial function $^{[50,51]}$. The ER is another important subcellular organelle critical for protein folding and the formation of disulfide bonds ${ }^{[52]}$. Investigating if $\mathrm{H}_{2} \mathrm{~S}$ can affect the ER function is important for elucidating the mechanisms underlying the protective effect of $\mathrm{H}_{2} \mathrm{~S}$ against Hcy-induced neurotoxicity.

In the present study, we demonstrated that administration of NaHS alleviated the expression of GRP78, CHOP, and cleaved caspase-12 in the hippocampus of rats treated intracerebroventricularly with Hcy. The fact that $\mathrm{H}_{2} \mathrm{~S}$ suppresses 
the expression of GRP78, CHOP, and cleaved caspase-12 is consistent with its effect on the toxicity of Hcy in cardiomyocytes $^{[21]}$. Moreover, the protective effects of $\mathrm{H}_{2} \mathrm{~S}$ against Hcyinduced ER stress were further confirmed in PC12 cells. Our results indicated that $\mathrm{H}_{2} \mathrm{~S}$ counteracts Hcy-induced ER stress, contributing to the role of $\mathrm{H}_{2} \mathrm{~S}$ in protecting against Hcyinduced neurotoxicity.

We further examined the possible signaling mechanisms for the protective effect of $\mathrm{H}_{2} \mathrm{~S}$ against Hcy-induced ER stress. BDNF, a member of the neurotrophin family, regulates the development, maintenance, plasticity, and function of the nervous system ${ }^{[53,54]}$. In vitro and in vivo studies indicate that BDNF functions as a neuroprotective agent and rescues neurons from various insults ${ }^{[55,56]}$. Increasing evidence has shown that BDNF plays an important role in counteracting ER stress $^{[35-37]}$, suggesting that the suppression of ER stress may contribute to BDNF-mediated neuroprotection. The action of $\mathrm{BDNF}$ is mediated by its binding to the TrkB receptor. In the present study, we investigated the contribution of the BDNFTrkB pathway to the inhibitory role of $\mathrm{H}_{2} \mathrm{~S}$ in Hcy-induced ER stress. We found that NaHS upregulated the expression of BDNF in the hippocampus of rats. Furthermore, our present data demonstrated that blocking the BDNF-TrkB pathway by the inhibitor of TrkB reversed the inhibitory effect of $\mathrm{H}_{2} \mathrm{~S}$ on the expression of GRP78, CHOP, and cleaved caspase- 12 in the hippocampus of rats treated with Hcy. Our results suggest that $\mathrm{H}_{2} \mathrm{~S}$ exerts its protective effects against Hcy-induced ER stress by upregulation of the BDNF-TrkB pathway.

In conclusion, the present observations identify the beneficial role of $\mathrm{H}_{2} \mathrm{~S}$ in protecting the hippocampus against Hcyinduced ER stress. The neuroprotective effect of $\mathrm{H}_{2} \mathrm{~S}$ involves the regulation of the BDNF-TrkB pathway. The findings of this work provide novel insights into the mechanisms of $\mathrm{H}_{2} \mathrm{~S}$ mediated protection against Hcy neurotoxicity. As Hcy is an independent risk factor for $\mathrm{AD}^{[10-14]}$ and ER stress is a crucial process in the pathogenesis of $\mathrm{AD}^{[15-17]}$, our findings suggest that $\mathrm{H}_{2} \mathrm{~S}$ has potential therapeutic value in the treatment of neurodegenerative diseases such as AD.

\section{Acknowledgements}

This study was supported by the National Natural Science Foundation of China (№ 81202518, 81200985, and 81071005), the Natural Science Foundation of Hunan Province, China (№ 11JJ3117, 12JJ9032), the Scientific Research Foundation for the Returned Overseas Chinese Scholars, Ministry of Education of the People's Republic of China ([2011]508) and the Construct Program of the Key Discipline in the Hunan province.

\section{Author contribution}

Xiao-qing TANG designed the research; Hai-jun WEI, Jin-hua XU, Man-hong LI, Ji-ping TANG, Chun-yan WANG, and Wei ZOU performed the research; Hai-jun WEI, Li WANG, Manhong LI, and Ji-ping TANG analyzed the data; and Xiao-qing TANG and Ping ZHANG wrote the paper.

\section{References}

1 Prudova A, Bauman Z, Braun A, Vitvitsky V, Lu SC, Banerjee R. S-adenosylmethionine stabilizes cystathionine beta-synthase and modulates redox capacity. Proc Natl Acad Sci U S A 2006; 103: 6489-94.

2 Selhub J. Homocysteine metabolism. Annu Rev Nutr 1999; 19: $217-$ 46.

$3 \mathrm{Kim} \mathrm{JH}$, Cho SY, Lee JH, Jeong SM, Yoon IS, Lee BH, et al. Neuroprotective effects of ginsenoside Rg3 against homocysteine-induced excitotoxicity in rat hippocampus. Brain Res 2007; 1136: 190-9.

4 Loureiro SO, Heimfarth L, Pelaez Pde L, Vanzin CS, Viana L, Wyse AT, et al. Homocysteine activates calcium-mediated cell signaling mechanisms targeting the cytoskeleton in rat hippocampus. Int J Dev Neurosci 2008; 26: 447-55.

5 Ho YS, Yu MS, Yang XF, So KF, Yuen WH, Chang RC. Neuroprotective effects of polysaccharides from wolfberry, the fruits of Lycium barbarum, against homocysteine-induced toxicity in rat cortical neurons. J Alzheimers Dis 2010; 19: 813-27.

6 Oldreive CE, Doherty GH. Neurotoxic effects of homocysteine on cerebellar Purkinje neurons in vitro. Neurosci Lett 2007; 413: 52-7.

7 Kuszczyk M, Gordon-Krajcer W, Lazarewicz JW. Homocysteine-induced acute excitotoxicity in cerebellar granule cells in vitro is accompanied by PP2A-mediated dephosphorylation of tau. Neurochem Int 2009; 55: $174-80$.

$8 \mathrm{Kim} \mathrm{HJ}$, Cho HK, Kwon YH. Synergistic induction of ER stress by homocysteine and beta-amyloid in SH-SY5Y cells. J Nutr Biochem 2008; 19: 754-61.

9 Park YJ, Jang Y, Kwon YH. Protective effect of isoflavones against homocysteine-mediated neuronal degeneration in SH-SY5Y cells. Amino Acids 2010; 39: 785-94.

10 Van Dam F, Van Gool WA. Hyperhomocysteinemia and Alzheimer's disease: A systematic review. Arch Gerontol Geriatr 2009; 48: 42530.

11 Seshadri S, Beiser A, Selhub J, Jacques PF, Rosenberg IH, D'Agostino $\mathrm{RB}$, et al. Plasma homocysteine as a risk factor for dementia and Alzheimer's disease. N Engl J Med 2002; 346: 476-83.

12 Miller JW. Homocysteine and Alzheimer's disease. Nutr Rev 1999; 57: 126-9.

13 Clarke R, Smith AD, Jobst KA, Refsum H, Sutton L, Ueland PM. Folate, vitamin B12, and serum total homocysteine levels in confirmed Alzheimer disease. Arch Neurol 1998; 55: 1449-55.

14 Dwyer BE, Raina AK, Perry G, Smith MA. Homocysteine and Alzheimer's disease: a modifiable risk? Free Radic Biol Med 2004; 36: 1471-5.

15 Hoozemans JJ, Veerhuis R, Van Haastert ES, Rozemuller JM, Baas F, Eikelenboom $\mathrm{P}$, et al. The unfolded protein response is activated in Alzheimer's disease. Acta Neuropathol 2005; 110: 165-72.

16 Salminen A, Kauppinen A, Suuronen T, Kaarniranta K, Ojala J. ER stress in Alzheimer's disease: a novel neuronal trigger for inflammation and Alzheimer's pathology. J Neuroinflammation 2009; 6: 41.

17 Cornejo VH, Hetz C. The unfolded protein response in Alzheimer's disease. Semin Immunopathol 2013; 35: 277-92.

18 Pizzo P, Pozzan T. Mitochondria-endoplasmic reticulum choreography: structure and signaling dynamics. Trends Cell Biol 2007; 17: 511-7.

$19 \mathrm{Kim}$ I, Xu W, Reed JC. Cell death and endoplasmic reticulum stress: disease relevance and therapeutic opportunities. Nat Rev Drug Discov 2008; 7: 1013-30.

20 Schroder M, Kaufman RJ. ER stress and the unfolded protein response. Mutat Res 2005; 569: 29-63.

21 Wei H, Zhang R, Jin H, Liu D, Tang X, Tang C, et al. Hydrogen sulfide 
attenuates hyperhomocysteinemia-induced cardiomyocytic endoplasmic reticulum stress in rats. Antioxid Redox Signal 2010; 12: 1079-91.

22 Outinen PA, Sood SK, Pfeifer SI, Pamidi S, Podor TJ, Li J, et al. Homocysteine-induced endoplasmic reticulum stress and growth arrest leads to specific changes in gene expression in human vascular endothelial cells. Blood 1999; 94: 959-67.

23 Chigurupati S, Wei Z, Belal C, Vandermey M, Kyriazis GA, Arumugam $\mathrm{TV}$, et al. The homocysteine-inducible endoplasmic reticulum stress protein counteracts calcium store depletion and induction of CCAAT enhancer-binding protein homologous protein in a neurotoxin model of Parkinson disease. J Biol Chem 2009; 284: 18323-33.

24 Zhang C, Cai Y, Adachi MT, Oshiro S, Aso T, Kaufman RJ, et al. Homocysteine induces programmed cell death in human vascular endothelial cells through activation of the unfolded protein response. J Biol Chem 2001; 276: 35867-74.

25 Yu X, Lv J, Zhu Y, Duan L, Ma L. Homocysteine inhibits hepatocyte proliferation via endoplasmic reticulum stress. PLoS One 2013; 8: e54265.

26 Kimura $\mathrm{H}$. Hydrogen sulfide as a neuromodulator. Mol Neurobiol 2002; 26: 13-9.

27 Kimura H, Shibuya N, Kimura Y. Hydrogen sulfide is a signaling molecule and a cytoprotectant. Antioxid Redox Signal 2012; 17: 45-57.

28 Hu LF, Lu M, Hon Wong PT, Bian JS. Hydrogen sulfide: neurophysiology and neuropathology. Antioxid Redox Signal 2011; 15: 405-19.

29 Zhou CF, Tang XQ. Hydrogen sulfide and nervous system regulation. Chin Med J (Engl) 2011; 124: 3576-82.

30 Tang XQ, Shen XT, Huang YE, Chen RQ, Ren YK, Fang HR, et al. Inhibition of endogenous hydrogen sulfide generation is associated with homocysteine-induced neurotoxicity: role of ERK1/2 activation. J Mol Neurosci 2011; 45: 60-7.

31 Tang XQ, Shen XT, Huang YE, Ren YK, Chen RQ, Hu B, et al. Hydrogen sulfide antagonizes homocysteine-induced neurotoxicity in PC12 cells. Neurosci Res 2010; 68: 241-9.

32 Chen ZF, Zhao B, Tang XY, Li W, Zhu LL, Tang CS, et al. Hydrogen sulfide regulates vascular endoplasmic reticulum stress in apolipoprotein E knockout mice. Chin Med J (Engl) 2011; 124: 3460-7.

33 Wang XY, Yang CT, Zheng DD, Mo LQ, Lan AP, Yang ZL, et al. Hydrogen sulfide protects $\mathrm{H} 9 \mathrm{c} 2$ cells against doxorubicin-induced cardiotoxicity through inhibition of endoplasmic reticulum stress. Mol Cell Biochem 2012; 363: 419-26.

34 Xie L, Tiong CX, Bian JS. Hydrogen sulfide protects SH-SY5Y cells against 6-hydroxydopamine-induced endoplasmic reticulum stress. Am J Physiol Cell Physiol 2012; 303: C81-91.

35 Chen G, Fan Z, Wang X, Ma C, Bower KA, Shi X, et al. Brain-derived neurotrophic factor suppresses tunicamycin-induced upregulation of CHOP in neurons. J Neurosci Res 2007; 85: 1674-84.

36 Shimoke K, Utsumi T, Kishi S, Nishimura M, Sasaya H, Kudo M, et al. Prevention of endoplasmic reticulum stress-induced cell death by brain-derived neurotrophic factor in cultured cerebral cortical neurons. Brain Res 2004; 1028: 105-11.

37 Zhu W, Bijur GN, Styles NA, Li X. Regulation of FOXO3a by brainderived neurotrophic factor in differentiated human SH-SY5Y neuroblastoma cells. Brain Res Mol Brain Res 2004; 126: 45-56.

38 Li Y, Zhang H, Jiang C, Xu M, Pang Y, Feng J, et al. Hyperho- mocysteinemia promotes insulin resistance by inducing endoplasmic reticulum stress in adipose tissue. J Biol Chem 2013; 288: 9583-92.

39 Park SJ, Kim KJ, Kim WU, Oh IH, Cho CS. Involvement of endoplasmic reticulum stress in homocysteine-induced apoptosis of osteoblastic cells. J Bone Miner Metab 2012; 30: 474-84.

40 Zbidi H, Redondo PC, Lopez JJ, Bartegi A, Salido GM, Rosado JA. Homocysteine induces caspase activation by endoplasmic reticulum stress in platelets from type 2 diabetics and healthy donors. Thromb Haemost 2010; 103: 1022-32.

41 Werstuck GH, Lentz SR, Dayal S, Hossain GS, Sood SK, Shi YY, et al. Homocysteine-induced endoplasmic reticulum stress causes dysregulation of the cholesterol and triglyceride biosynthetic pathways. J Clin Invest 2001; 107: 1263-73.

42 Stipanuk MH. Sulfur amino acid metabolism: pathways for production and removal of homocysteine and cysteine. Annu Rev Nutr 2004; 24: 539-77.

43 White AR, Huang X, Jobling MF, Barrow CJ, Beyreuther K, Masters CL, et al. Homocysteine potentiates copper- and amyloid beta peptidemediated toxicity in primary neuronal cultures: possible risk factors in the Alzheimer's-type neurodegenerative pathways. J Neurochem 2001; 76: 1509-20.

44 Ho PI, Collins SC, Dhitavat S, Ortiz D, Ashline D, Rogers E, et al. Homocysteine potentiates beta-amyloid neurotoxicity: role of oxidative stress. J Neurochem 2001; 78: 249-53.

45 Kimura Y, Kimura $\mathrm{H}$. Hydrogen sulfide protects neurons from oxidative stress. FASEB J 2004; 18: 1165-7.

46 Tang XQ, Yang CT, Chen J, Yin WL, Tian SW, Hu B, et al. Effect of hydrogen sulphide on beta-amyloid-induced damage in PC12 cells. Clin Exp Pharmacol Physiol 2008; 35: 180-6.

47 Whiteman M, Armstrong JS, Chu SH, Jia-Ling S, Wong BS, Cheung NS, et al. The novel neuromodulator hydrogen sulfide: an endogenous peroxynitrite 'scavenger'? J Neurochem 2004; 90: 765-8.

48 Whiteman M, Cheung NS, Zhu YZ, Chu SH, Siau JL, Wong BS, et al. Hydrogen sulphide: a novel inhibitor of hypochlorous acid-mediated oxidative damage in the brain? Biochem Biophys Res Commun 2005; 326: 794-8.

49 Eto K, Asada T, Arima K, Makifuchi T, Kimura H. Brain hydrogen sulfide is severely decreased in Alzheimer's disease. Biochem Biophys Res Commun 2002; 293: 1485-8.

50 Tang XQ, Ren YK, Zhou CF, Yang CT, Gu HF, He JQ, et al. Hydrogen sulfide prevents formaldehyde-induced neurotoxicity to PC12 cells by attenuation of mitochondrial dysfunction and pro-apoptotic potential. Neurochem Int 2012; 61: 16-24.

51 Hu LF, Lu M, Wu ZY, Wong PT, Bian JS. Hydrogen sulfide inhibits rotenone-induced apoptosis via preservation of mitochondrial function. Mol Pharmacol 2009; 75: 27-34.

52 Xu C, Bailly-Maitre B, Reed JC. Endoplasmic reticulum stress: cell life and death decisions. J Clin Invest 2005; 115: 2656-64.

53 Binder DK, Scharfman HE. Brain-derived neurotrophic factor. Growth Factors 2004; 22: 123-31.

54 Huang EJ, Reichardt LF. Neurotrophins: roles in neuronal development and function. Annu Rev Neurosci 2001; 24: 677-736.

55 Zuccato C, Cattaneo E. Brain-derived neurotrophic factor in neurodegenerative diseases. Nat Rev Neurol 2009; 5: 311-22.

56 Pezet S, Malcangio M. Brain-derived neurotrophic factor as a drug target for CNS disorders. Expert Opin Ther Targets 2004; 8: 391-9. 